\title{
scripted
}

Volume 12, Issue 2, September 2015

\section{Cyber-Misogyny: ShOULd ‘REvenge PoRn’ BE REgulated in SCOTLAND, AND IF SO, HOW?}

Rachel Hill

\begin{abstract}
This paper aims to assess whether 'revenge porn' merits regulation in Scotland, and, if so, how this ought to be achieved. In doing so, this paper critically assesses 'revenge porn' from feminist perspectives to highlight the harms caused by the conduct, analyses the extent to which victims are adequately protected by the current legislative framework in Scotland, and discusses whether criminalisation is the most desirable method of regulation. Finally, an indepth comparative analysis of approaches to criminalisation in several other jurisdictions seeks to ascertain how Scottish legislation addressing 'revenge porn' could be effectively drafted. The paper concludes that 'revenge porn' is a form of "cyber-misogyny": one online example of gendered hatred, harassment and abuse primarily directed towards women and girls. In light of the severity of this behaviour, it's destructive impact on individual victims and on society as a whole; it is argued that criminalisation is the most appropriate method of regulation.
\end{abstract}

DOI: $10.2966 /$ scrip.120215.117

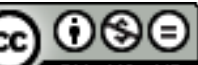

(C) Rachel Hill 2015. This work is licensed under a Creative Commons Attribution-NonCommercial-ShareAlike 4.0 International License. Please click on the link to read the terms and conditions. 


\section{Introduction}

The phenomenon colloquially known as 'revenge porn' can be defined as sexually explicit images, shared publicly online without the subjects consent. ${ }^{1}$ Typically, the images are exchanged consensually during an intimate relationship and are unintended to be seen by anyone else. Nonetheless, 'revenge porn' can refer to a variety of scenarios; the images may be obtained by hacking or theft, the documentation of a sexual assault, or captured without the victim's knowledge. Given the range of scenarios typically referred to by the term "revenge porn", it arguably trivialises the matters involved and has been criticised as misleading. ${ }^{2}$ Implicit in the term 'revenge' is a tacit justification of the violation, implying that the victim did something to cause the incident. In the words of Ellie Hutchinson at Scottish Women's Aid, "it's not about revenge and it's not about porn. It's about humiliation, manipulation, coercion and fear". ${ }^{3}$ Many commentators therefore prefer the term 'non-consensual pornography' (henceforth referred to as NCP). When viewed from a feminist perspective, NCP can be considered as an online example of gendered hatred, harassment and abuse.

Although the distribution of NCP is not technically illegal in Scotland at present, it may fall under several offences in some instances. However, a recent rise in awareness of the issue, partly due to high-profile cases involving celebrities and growing public pressure from women's campaign groups and media outlets, has led politicians and scholars to push for its criminalisation. ${ }^{4}$ Lord Advocate Frank Mulholland addressed this perceived inadequacy of existing remedies by announcing that formal attempts to introduce a new offence targeting NCP will be initiated. ${ }^{5}$ This paper explores whether this type of conduct is worthy of regulation in Scotland, and if so, how this ought to be done.

\subsection{The Phenomenon of 'Revenge Porn'}

To assess whether NCP is worthy of regulation in Scotland, it is crucial to form an understanding of what this conduct 'is' and the effect it has, since this ultimately affects how it ought to be regulated. Although men are often victimised by the non-consensual circulation of sexual images, it appears to be a highly gendered activity disproportionately impacting women; one study has suggested that an estimated $90 \%$ of victims are female. ${ }^{6}$ While it may

\footnotetext{
${ }^{1}$ http://www.revengepornhelpline.org.uk/about-revenge-porn/ (accessed 9 November 2015).

${ }^{2}$ CR Proudman, "Revenge porn: enough still isn't being done to stop it" (2014) available at http://www.independent.co.uk/life-style/health-and-families/features/revenge-porn-enough-still-isnt-being-doneto-stop-it-9578892.html (accessed 9 November 2015).

${ }^{3}$ Young Women's Network, “16 Days of Action Against Gender Based Violence” (2014) available at https://swcyoungwomen.wordpress.com/2014/12/03/16-days-of-action-against-gender-based-violence-getinvolved-with-scottish-womens-aid/ (accessed 9 November 2015).

${ }^{4}$ For example: Scottish Women's Aid Campaign, Stop Revenge Porn Scotland, Ban Revenge Porn UK, End Violence Against Women, VOIC, Liberal Democrats Campaign, SNP MSP Christina McKelvie.

${ }^{5}$ BBC News Scotland, "New law to tackle 'revenge porn' in Scotland” (2014) available at http://www.bbc.co.uk/news/uk-scotland-scotland-politics-29717347 (accessed 9 November 2015).

${ }^{6}$ Cyber Civil Rights Initiative, "Revenge Porn by the Numbers” (2014) available at http://www.endrevengeporn.org/revenge-porn-infographic/ (accessed 9 November 2015). Since 'revenge porn' is a relatively new phenomenon, there is a lack of reliable empirical data on the nature of revenge porn and its prevalence. The results of the Cyber Civil Rights Initiative's statistics have been recognized as reflective of a
} 
initially seem peculiar that women and girls are predominately targeted, once viewed in a wider context of historical sexism, this seemingly coincidental gender disparity could be seen to be a depressing reflection of hostility directed towards women. "The Internet is a hall of mirrors... its use reflects the inequalities and injustices of the societies into which it is inserted..."7 Not only are women more likely to be victims of NCP, but the consequences are also more severe for women than men, due to sexual double standards and deeply-ingrained beliefs that women's behaviour provokes sexual violence. The phenomenon of 'revenge porn' will thus be examined from feminist perspectives in order to consider how this conduct ought to be regulated, if worthy of regulation at all.

\subsection{Cyber-Misogyny}

Although NCP is often trivialised by commentators, this indifference is precisely the kind of attitude that has historically persisted towards many other 'women's issues' ${ }^{8}$ It took years of effort from women's movements and feminist activists to expose and to challenge rape, domestic violence, and sexual harassment as systematic and harmful, which previously were tolerated, trivialized, and dismissed. ${ }^{9}$ Although domestic abuse is now recognised as a form of gendered violence and a "major public health and human rights problem", historically it was virtually ignored as a public policy issue. ${ }^{10}$ It was regarded as a "private concern", which was neither serious nor criminal, until it was later framed as a form of gendered violence. ${ }^{11}$ In a similar fashion to the historic use of this private/public dichotomy to trivialise domestic violence, a false dichotomy between 'offline' and 'online' worlds is often used to trivialise harms caused by NCP. ${ }^{12}$ Nonetheless, violations of sexual autonomy online can have the exact same effects as those in 'the real world'. If NCP is reframed as a form of 'cyber misogyny', and the harms caused by it are illuminated, it may become evident that current norms of acceptable conduct must be changed. ${ }^{13}$

NCP has not only been dismissed in the same way that domestic violence was historically dismissed, but it also often forms a tactic of abuse within domestic violence itself. In some cases, the images are the product of coercion, and in extreme instances the images may be a

female-heavy sample, so should be viewed as estimations rather than facts until more reliable research is undertaken from a larger sample.

${ }^{7}$ N Shalhoub-Kevorkian and T Berenblum, "Panoptical Web: Internet and Victimization of Women" (2010) 17 International Review of Victimology 90-91.

${ }^{8}$ DK Citron, "Laws Expressive Value in Combatting Cyber Gender Harassment" (2010) 108 Michigan Law Review 373, at395.

${ }^{9}$ The rule that exempted husbands from marital rape convictions was not abolished in Scotland until Stallard $v$ HM Advocate 1989 SLT 469. No term even existed to describe sexual harassment of women in the workplace until the 1970's and sexual harassment was first legally recognised as a form of workplace discrimination in the UK in Strathclyde Regional Council v Porcelli [1986] IRLR 134.

${ }^{10}$ CA Kelly, 'Domestic Violence and the Politics of Privacy' (Cornell University Press: New York, 2003), at 46.

${ }^{11}$ L Harne and J Radford, 'Tackling Domestic Violence: Theories, Policies and Practices' (Open University Press: Glasgow, 2008), at 17.

${ }^{12}$ D Henry and A Powell, 'The Dark Side of the Virtual World: Towards a Digital Sexual Ethics' in Preventing Sexual Violence: Interdisciplinary Approaches to Overcoming Rape Culture (2014), at 92.

${ }^{13}$ DK Citron, "Laws Expressive Value in Combatting Cyber Gender Harassment" (2010) 108 Michigan Law Review 373, at 377. 
documented sexual assault. ${ }^{14}$ Abusive partners often threaten disclosure of intimate photos as a way of controlling someone within a relationship or after the relationship ends, ${ }^{15}$ by turning the unwilling victim into sexual entertainment for strangers, with the sole purpose of intimidating, humiliating, silencing, and degrading them. In the same way that many feminists believe that sexual assault revolves around power and dominance rather than sex, many instances of NCP seem to be assertions of control, revolving around inherent disrespect for women's autonomy. ${ }^{16}$

The UN Convention on the Elimination of Discrimination against Women described genderbased violence as violence "directed against a woman because she is a woman or that affects women disproportionately"; including acts that "inflict physical, mental or sexual harm or suffering, threats of such acts, coercion and other deprivations of liberty". ${ }^{17}$ This definition is deliberately expansive to accommodate modes of sexual violence that are being uncovered with time, and NCP could be regarded as a form of gender-based violence that has emerged as technology has developed. ${ }^{18}$ This gendered harassment does not seem to have materialized in a vacuum, but rather, is arguably a "manifestation of the historically unequal power relations between men and women". ${ }^{19}$ In many cases, such conduct reveals efforts to use sexual humiliation to combat women's parity of participation in the public sphere, and the immediate, devastating, and irreversible effects of this conduct cannot be understated. ${ }^{20}$

While anonymity allows Internet users to act out aggressions that they potentially never would in the 'real world', for women targeted by such behaviour, the tolls exacted on them emotionally, professionally, and even physically, are incredibly "real world". ${ }^{21} \mathrm{NCP}$ regularly destroys relationships, reputations, and careers. ${ }^{22}$ Merely entering a victim's name into a

\footnotetext{
${ }^{14}$ For example, the cases of Audrie Pott and Rehtaeh Parsons - see J. Valenti, “Our daughter is dead. We're the surviving victims: rape, bullying and suicide, after a viral flood" (2014) available at http://www.theguardian.com/commentisfree/2014/oct/03/-sp-rape-bullying-rehteaeh-parsons-audrie-pottfamilies (accessed 9 November 2015); P. Wright, "Rehtaeh Parsons: Canadian police to re-open case into rape of suicide teen" (2013) available at

http://www.telegraph.co.uk/news/worldnews/northamerica/canada/9991536/Rehtaeh-Parsons-Canadian-policere-open-case-into-rape-of-suicide-teen.html (accessed 9 November 2015).

${ }^{15}$ Scotland's Crown Office and Procurator Fiscal Service "Guidance on cases involving Communications sent via Social Media” (2014), p.6; Women’s Aid Press Release (2014) available at

http://www.womensaid.org.uk/domestic-violence-pressinformation .asp? itemid $=3328 \&$ itemTitle $=$ Women $\% 27 \mathrm{~s}+$ Aid + welcomes + Revenge + Porn + Law $\&$ section $=000100$ $0100150001 \&$ sectionTitle $=$ Press + releases $($ accessed 9 November 2015).

${ }^{16}$ CA Mackinnon, 'Women's Lives Men's Laws', (Harvard University Press, 2007), at130.

${ }^{17}$ United Nations General Assembly Declaration on the Elimination of Violence Against Women A/RES/48/104 (20th December 1993), General Recommendation No. 19(6).

${ }^{18}$ J. Kee, "Cultivating Violence Through Technology? Exploring the Connections between Information Communication Technologies and Violence Against Women" (2005) Association of Progressive Communications Women's Networking Support Programme, at 5

${ }^{19}$ United Nations Economic and Social Council, $57^{\text {th }}$ Session of the Commission on the Status of Women, E/CN.6/2013/4, para.15.

${ }^{20}$ M. Salter and T. Crofts, "Responding to Revenge Porn: Challenges to Online Legal Impunity" in New Views on Pornography: Sexuality, Politics, and the Law (Praeger, 2015), at 248.

${ }^{21}$ B. Roese, "Defamation, Humiliation, and Lost Reputations: Mitigating the Damage to Women Harassed Online” (2014), 35 Women's Rights Law Reporter 123, at 4.

${ }^{22}$ For example, a Canadian judge faced dismissal and was forced to resign after becoming a victim of revenge porn: see Oxford Human Rights Hub, “(In)justice served? Lori Douglas Case Leaves More Questions than
} 
search engine can display their sexual images, and recent research has shown that around $70 \%$ of employers have rejected applicants due to information found online. ${ }^{23}$ It is also not uncommon for perpetrators to send images directly to the victim's friends, family and employer. ${ }^{24}$ Lord Nicholls described reputation as "an integral and important part of the dignity of the individual", and it is the perpetrators reputation that should be left tarnished rather than the victim's. ${ }^{25} \mathrm{NCP}$ also threatens victims' safety by raising their vulnerability to offline stalking and physical violence. ${ }^{26}$ The majority of victims have reportedly had their images posted next to their personal contact information, encouraging strangers to stalk and harass them. ${ }^{27}$ Victims also frequently receive threats of assault, rape and murder from those viewing their images. ${ }^{28}$ Many are even driven to suicide. ${ }^{29}$

Misogynistic 'revenge porn websites' which specialise in archiving user-submitted images have also become increasingly common in tandem with the recent rise in 'popularity' of NCP. The creators of such websites seek to eroticise and commodify victim's distress by charging men for access to images and extorting victims for money to have their images removed. ${ }^{30}$ While NCP can affect men, there appears to be no such websites specializing in images of men, arguably because it is not thought to be inherently degrading or humiliating for men to have sex. ${ }^{31}$ These websites do not appear to be about images of naked women, since there are thousands on the Internet consensually, but rather, they are about relishing in the sexual violation of women.

\subsection{Victim Blaming}

Answers for Canadians", (2014) available at http://ohrh.law.ox.ac.uk/injustice-served-lori-douglas-case-leavesmore-questions-than-answers-for-canadians/ (accessed 9 November 2015).

${ }^{23}$ Cross-Tab, "Online Reputation in a Connected World" (2010), p.3, available at http://www.jobhunt.org/guides/DPD_Online-Reputation-Research_overview.pdf(accessed 9 November 2015).

${ }^{24}$ For example, the first person to be convicted under California's revenge porn law posted the image on the Facebook page of the victim's employer: see The Guardian, "California man first to be convicted under state's revenge porn law" (2014) available at http://www.theguardian.com/us-news/2014/dec/02/california-convictedrevenge-porn-law (accessed 9 November 2015).

${ }^{25}$ Reynolds $v$ Times Newspapers [2001] 2 AC 127, Lord Nicholls at 201.

${ }^{26}$ See note 13 (Citron) at p.375.

${ }^{27}$ In a CCRI study, over $50 \%$ of victims reported that their images appeared next to their full name and social network profile - see D.K. Citron and M.A. Franks, "Criminalizing Revenge Porn” (2014) 49 Wake Forest Law Review 350.

${ }^{28}$ D.K. Citron, "Hate Crimes in Cyberspace” (Harvard University Press 2014), at16-17.

${ }^{29}$ See note 14; see also - Amanda Todd, Hope Witsell and Jessica Logan - BBC News, "Man charged in Netherlands in Amanda Todd suicide case" (2014) available at http://www.bbc.co.uk/news/world-europe27076991 (accessed 9 November 2015); The Independent, "US Youth suicides linked to 'sexting' but trend rises" (2009) available at http://www.independent.co.uk/life-style/gadgets-and-tech/news/us-youth-suicideslinked-to-sexting-but-trend-rises-1834127.html (accessed 9 November 2015)

${ }^{30}$ See note 20 (Salter and Crofts) at p.248.

${ }^{31}$ J Filipovic, "Revenge porn is about degrading women sexually and professionally" (2013) available at http://www.theguardian.com/commentisfree/2013/jan/28/revenge-porn-degrades-women (accessed 9 November 2015). 
"Let us start putting [the blame] back where it belongs - on the perpetrators who thrive on the harassment, degradation, and humiliation of their victims" 32

Many also attempt to trivialise the severity of NCP by arguing that it is the victim's fault for taking sexual photos in the first place. Needless to say, "don't take photos" is an inadequate solution. While some attempt to portray this advice as reasonable (based on the rationale that photos cannot be distributed if they do not exist), since it is primarily women targeted by NCP, the advice is really directed towards women, and aimed particularly at restricting their sexual behaviour. ${ }^{33}$ Women should not be punished for exercising their right to sexual autonomy or blamed for trusting someone who later viciously betrays them. After all, it has been said that one of the purposes of domestic violence laws is to protect individuals against their misplaced trust. ${ }^{34}$ In a similar fashion to many instances of sexual assault, women are expected to 'take responsibility' for their lawful personal choices, rather than placing responsibility on the perpetrator for their inexcusable actions. Even legal scholars have maintained that "the origin of these pictures may matter..." and that NCP is a "natural urge to 'set right' imbalances of virtue". 35 Although such advice is often well meaning, it is based upon problematic assumptions that it is the victim's responsibility to prevent harassment. ${ }^{36}$ Additionally, it completely ignores the fact that NCP can often be the result of surreptitious surveillance.

Placing the blame on the individual depicted is also extremely harmful because it perpetuates a culture of victim blaming and "slut-shaming": the act of criticizing a woman for sexual activity to inflict shame upon her. This kind of mind-set can be said to stem from the belief that female sexuality itself is shameful. ${ }^{37}$ Women are expected to "be desirable but not desiring", irrespective of the fact that shaming a person for consensual sexual activity is illogical. ${ }^{38}$ Blaming the victim for the actions of the perpetrator contributes to these social mores and perpetuates gender inequality by reaffirming sexist double standards, where women are heavily criticised for sexual activity, while men are praised for virtually identical behaviour. Online sexual violence not only harms those targeted, but also adds to a culture that tolerates sexual abuse and holds women responsible for their own victimisation. ${ }^{39}$

\footnotetext{
${ }^{32}$ Bekah Wells, founder of 'Women Against Revenge Porn' - see note 28 (Citron) at 106.

${ }^{33}$ MA Franks, “Adventures in Victim Blaming: Revenge Porn Edition” (2013) available at http://concurringopinions.com/archives/2013/02/adventures-in-victim-blaming-revenge-porn-edition.html (accessed 9 November 2015).

${ }^{34}$ O Rachmilovitz, "Bringing Down the Bedroom Walls: Emphasizing Substance over Form in Personalized Abuse" (2008) 14 William \& Mary Journal of Women and the Law 495, at 500.

${ }^{35}$ S.R. Stroud, "The Dark Side of the Online Self: A Pragmatist Critique of the Growing Plague of Revenge Porn” (2014) 29 Journal of Mass Media Ethics, 168-183, at 176 and 180.

${ }^{36}$ J Fairbairn, "Rape Threats and Revenge Porn: Defining Sexual Violence in the Digital Age" in $e$ Girls, eCitizens (University of Ottawa Press, 2015), at 229.

${ }^{37}$ R Budde, "Taking the Sting Out of Revenge Porn: Using Criminal Statutes to Safeguard Sexual Autonomy in the Digital Age" (2015) 16 Georgetown Journal of Gender and the Law 407-444, at.419.

${ }^{38}$ JA Reid, S Elliott and GR Webber, "Casual Hookups to Formal Dates: Refining the Boundaries of the Sexual Double Standard” (2011) 25 Gender and Society 545-568, at 549.

${ }^{39}$ See note 36 (Fairbairn) at p.235
} 
For example, authorities have often been shown to respond with a lack of concern when sexual images of a woman taken consensually are later shared against her will. ${ }^{40}$ Whereas, images shared after being taken non-consensually tend to be taken seriously and are considered to be a serious infringement of sexual autonomy. ${ }^{41}$ This arguably suggests an implicit endorsement of punishing 'immodesty'. Such a pattern of official disinterest in the plight of the victim, and implicit approval of stigmatisation and re-victimisation is not unique to NCP, but has been well documented in feminist research on sexual violence; it is said that many sexual crimes intend to isolate and to defile the victim, "so that she will be publicly stigmatized and scorned should the crime be disclosed". ${ }^{42}$

\subsection{Contextual Consent}

Privacy "is not simply an absence of information about us in the minds of others; rather it is the control we have over information about ourselves". 43

Another seemingly reasonable argument put forward is that when a person shares a sexual image with someone else, they have reduced their reasonable expectation of privacy. Nonetheless, a person's expectation of privacy is not reduced when an image is consensually shared with someone else, since his or her consent was premised on the expectation that the image would remain private. Consent is not an on/off switch ${ }^{44}$, and sharing an image with a trusted confidant should not be equated to consent for it to be exposed to the public at large. ${ }^{45}$ Such a refusal to recognise the contextual nature of consent seems closely tied to traditional, idiosyncratic views about sex, where a victim's consent in one context is taken as consent for other contexts. ${ }^{46}$ It is the same dangerous mentality that has historically been used against victims of sexual assault, where a victim's sexual history is used in an attempt to undermine the possibility of his/her lack of consent. ${ }^{47}$

Outside of sexual practices, it is widely accepted that consent is context-specific and that information is rarely wholly private or wholly public. An illustration of this lack of value placed on sexual consent is the recent dissemination of sexual images of celebrities stolen by hackers, often referred to as a "nude leak scandal". ${ }^{48}$ The fact that the conversation is primarily focused on nude photos, rather than on the sexual violation of a woman who has

\footnotetext{
${ }^{40}$ See note 20 (Salter and Crofts) at p.233; see note 28 (Citron) at p.83 \& 86.

${ }^{41}$ For example, voyeurism: Sexual Offences (Scotland) Act, s.9.

${ }^{42}$ JL Herman, “Justice From the Victim's Perspective” (2005) 11 Violence Against Women Vol. 11 571-602, at573.

${ }^{43}$ C Fried, "Privacy" (1968), 77 Yale Law Journal 475, at482.

${ }^{44}$ See note 28 (Citron) at p.147.

${ }^{45}$ P.J. Larkin, “Revenge Porn, State Law, Free Speech” (2014), Loyola of Los Angeles Law Review Vol. 48, p.24.

${ }^{46}$ See note 27 (Citron and Franks) at p.348.

${ }^{47}$ J Temkin, "Rape and the Legal Process" (2 ${ }^{\text {nd }}$ Edition, Oxford: Oxford University Press 2002) at 196; Greatbanks [1959] Criminal Law Review 450.

${ }^{48}$ The Independent, "The Fappening: Jennifer Lawrence and Kate Upton nude leak scandal has significantly changed global sexting habits" (2015) available at http://www.independent.co.uk/life-style/gadgets-andtech/the-fappening-jennifer-lawrence-and-kate-upton-nude-leak-scandal-has-significantly-changed-global10120192.html (accessed 9 November 2015).
} 
forcefully had her naked body displayed to the world, powerfully reflects how consent and female sexuality is regarded by society. Many do not feel uncomfortable looking at these images, despite the fact that anyone viewing, sharing, or promoting NCP could be considered to be actively participating in the sexual violation of another person. The wrongdoings undergirding sexual assault - lack of consent, violation of sexual autonomy and objectification - are the same wrongs present in the dissemination of NCP.

\subsection{Objectification}

Objectification has long been a cherished feminist concept and considered as a central dynamic of gender inequality. ${ }^{49}$ It describes the reduction of women to objects existing purely for men's use and pleasure, which is precisely what NCP seeks to do - identify a person by their body parts to make them feel like a thing which can be easily violated and used by strangers. Public objectification such as this can also be regarded as a form of shame punishment, ${ }^{50}$ and extreme objectification often takes the form of rape fantasies (often directed towards victims of NCP), where pleasure is derived from the violent violation of a person's autonomy. ${ }^{51}$ Due to the harms that can result from objectification, links have been drawn between pornography and discriminatory practices against women. ${ }^{52}$ Therefore, it is not unreasonable to suggest that turning women into objects of pornography against their will may further contribute to gender inequality. MacKinnon's critique of pornography seems even more relevant today with regards to NCP; it is the dehumanization and violation of women that makes it 'sexy'. 53

\section{Should 'Revenge Porn' be Criminalised?}

While it is clear that the serious harms caused by NCP merit its regulation, there is disagreement as to whether criminalising the behaviour is the most appropriate method. Perhaps the most common argument put forward against criminalisation is that it is unnecessary, since existing remedies could tackle the problem. ${ }^{54}$ Nonetheless, it is questionable whether existing offences can be truly effective in providing redress for victims. The current legal framework will be examined to establish whether a specific offence is necessary to tackle NCP in Scotland.

\subsection{Critique of Civil Remedies}

\subsubsection{Breach of Confidence}

\footnotetext{
${ }^{49}$ See note 16 (Mackinnon) at 111.

${ }^{50}$ MC Nussbaum, "Objectification and Internet Misogyny", in MC Nussbaum and S Levmore (eds) The Offensive Internet: Speech, Privacy, and Reputation, (Harvard University Press, 2012), at 68.

${ }^{51}$ DK Citron, "Civil Rights in Our Information Age" in The Offensive Internet: Speech, Privacy, and Reputation, (Harvard University Press, 2012), at 35.

52 A Dworkin, 'Pornography: Men Possessing Women' (London: Women's Press 1981); G Dines, B Jensen and A Russo, 'Pornography: The Production and Consumption of Inequality', (Taylor and Francis 1998).

${ }^{53}$ See note 16 (Mackinnon) at 338.

${ }^{54}$ See note 37 (Budde); JK Stokes, "The Indecent Internet: Resisting Unwarranted Internet Exceptionalism in Combating Revenge Porn" (2014) 29 Berkeley Technology Law Journal Vol 929; D Bambauer, 'Exposed' (2014) 98 Minnesota Law Review 2025.
} 
Breach of confidence seeks to protect violations "of a citizen's autonomy, dignity and selfesteem" 55 and may offer a remedy for victims of NCP. Essentially, the court would consider whether the subject had a reasonable expectation that the images would remain private and confidential. ${ }^{56} \mathrm{NCP}$ could meet this requirement, since sexual images shared privately with a partner are not readily available in the public domain. Photographs in particular are an intrusive medium, "affording viewers the opportunity to minutely focus on the most intimate details of an individual's private life". ${ }^{57}$ However, common law remedies offer little scope to save the victim's pain, humiliation and expense - damages cannot be quantified to alleviate the suffering inflicted on the claimant. Victims would also be powerless to prevent publication of the images from the outset, so an interdict would be of limited value when the victim's images have already been circulated online.

\subsubsection{Copyright}

Some commentators believe that copyright law could be the most efficient method for victims of NCP to have their images removed. ${ }^{58}$ While in theory, using copyright to file a takedown notice with the hosting website could be the most straightforward means of removal, in reality this solution is illusory. A survey has suggested that $80 \%$ of images distributed non-consensually are "selfies", where the victim owns copyright as 'author' of the work. ${ }^{59}$ Therefore, for many victims, copyright is not a solution.

Even for victims who own the copyright, image removal is not a quick process. During the takedown delay, which could be a number of weeks, images may be re-published elsewhere, and takedown notices can be ignored or rejected without explanation. ${ }^{60}$ Many sites simply ignore removal requests entirely because they know that the average complainant cannot afford to pursue litigation; Google, for example, received over 34,000,000 URL removal requests in one month alone. ${ }^{61}$

Copyright experts have also objected that expansion in this way is an undesirable deviation from the proper goals of the doctrine, since copyright law was not designed to supress content, but rather to stimulate the creation of new works by ensuring fair compensation for creators. ${ }^{62}$ The suggestion that copyright law is an adequate response to NCP

\footnotetext{
${ }^{55}$ Mosley v News Group Newspapers Ltd [2008] EWHC 1777(QB); [2008] E.M.L.R 20 at [7] per Eady J.

${ }^{56}$ Campbell v Mirror Group Newspapers Ltd [2004] UKHL 22 at [14] per Lord Nicholls.

${ }^{57}$ Contostavlos v Michael Mendahun [2012] EWHC 850 (QB) at [105] per Tugendhat J.

${ }^{58}$ A Levendowski, “Using Copyright to Combat Revenge Porn” (2014) 3 N.Y.U. Journal of Intellectual Property \& Entertainment Law 422-446, at 446.

${ }^{59}$ A 'selfie' is an image where the photographer is also the subject of the photograph: see End Revenge Porn Infographic (2015) available at http://www.endrevengeporn.org/anatomy-effective-revenge-porn-law/ (accessed 9 November 2015).

${ }^{60}$ See note 28 (Citron) at p. 172 .

${ }^{61}$ Google Transparency Report, 'Requests to Remove Content Due to Copyright: Overview', Statistic from 23/12/2014 to 23/01/2015, available at https:/www.google.com/transparencyreport/removals/copyright/ (accessed 9 November 2015).

62 JK Stokes, “The Indecent Internet: Resisting Unwarranted Internet Exceptionalism in Combating Revenge Porn” (2014) 29 Berkeley Technology Law Journal 929-954, at 937.
} 
mischaracterises the harm as one of property rights rather than a sexual violation - distorting copyright law is an inappropriate solution to the problem. ${ }^{63}$

\subsubsection{Data Protection}

Data subjects have the right to prevent the processing of data likely to cause damage or distress, particularly 'sensitive data' such as sexual images. ${ }^{64}$ After receiving notice, the data controller must comply with the subject's request within 21 days, or state intention to comply. ${ }^{65}$ Otherwise, the data subject may apply to the court. The "right to be forgotten" is another potential remedy available under data protection law, allowing individuals to have links erased from search engines. ${ }^{66}$ It has been described as "a godsend to revenge porn victims" because when a link is wiped from Google's index, "the content essentially ceases to exist". ${ }^{67}$ While 'the right to forget' may appear to be a promising solution, the images themselves actually remain untouched. What is removed is a link in the search engine's index, meaning that certain material will not be shown in search results. Therefore, it could still be extremely easy for images of a specific individual to be found, simply by using a foreign search engine or a search function within a 'revenge porn' website. A recent report published by the House of Lords EU Committee criticised the impracticality of the 'right to forget', saying that it is "at best a right to make information less easily accessible; at worst it may achieve the opposite of what was desired". ${ }^{6}$

\subsubsection{Limitations of Civil Remedies}

While civil law can offer modest deterrence and redress, in reality, practical issues render these remedies more theoretical than real. Since such remedies may only be utilised after the event has occurred, they cannot prevent the publication of images from the outset. Additionally, none of the remedies can be truly successful in removing the images from the Internet, which is the outcome that most victims desire. In any case, civil litigation is extremely expensive and time-consuming, and generally requires the claimant to fund the cost of litigation from the outset. While celebrities may have the financial capabilities to instigate civil proceedings, the vast majority of victims do not have such financial freedom, making this route inaccessible. ${ }^{69}$ Even for those who can afford litigation, if the perpetrator has few assets, this will provide little reward. Those affected may also be reluctant to sue for

\footnotetext{
${ }^{63}$ R. Tushnet, "Performance Anxiety: Copyright Embodied and Disembodied" (2013), Georgetown Public Law and Legal Theory, Research Paper No. 13-040, p.1030.

${ }^{64}$ Data Protection Act 1998, s.10.

${ }^{65}$ Ibid, s.10(3).

${ }^{66}$ As established in Google Spain SL, Google Inc. v Agencia Española de Protección de Datos, Mario Costeja González (Case C-131/12, 13 May 2014).

${ }^{67}$ L. Edwards, "Revenge porn: why the right to be forgotten is the right remedy" (2014) available at http://www.theguardian.com/technology/2014/jul/29/revenge-porn-right-to-be-forgotten-house-of-lords (accessed 9 November 2015).

${ }^{68}$ House of Lords European Union Committee $2^{\text {nd }}$ Report of Session 2014-15, "EU Data Protection law: a 'right to be forgotten'?" (2014), p.9, available at http://www.publications.parliament.uk/pa/ld201415/ldselect/ldeucom/40/40.pdf (accessed 9 November 2015).

${ }^{69}$ J Mitchell, "Censorship in Cyberspace: Closing the Net on "Revenge Porn”" (2014) 25 Entertainment Law Review 283-290, at.285.
} 
fear of unleashing more unwanted publicity ${ }^{70}$, which often results in re-victimisation. ${ }^{71}$ Therefore, civil remedies cannot be reasonably considered as an adequate solution.

\subsection{Critique of Criminal Offences}

\subsubsection{Offensive Communications}

Perpetrators of NCP may be prosecuted for sending material of a "grossly offensive or of an indecent, obscene or menacing character" ${ }^{72}$ However, a high threshold test must be met before communications will amount to criminal conduct, ${ }^{73}$ so unless of an extreme nature or accompanied by serious threats, NCP is unlikely to fall within the sphere of this statute. ${ }^{74}$ Additionally, this provision has been criticised for its vague ambit and unpredictability, ${ }^{75}$ since the offence covers a wider set of circumstances than originally anticipated. The wording of the provision can be traced back to s.10(2) of the Post Office (Amendment) Act 1935, which intended to regulate one-to-one communications and to safeguard public utilities built with public money. ${ }^{76}$ Such a justification for the broad ambit of $\mathrm{s} .127$ no longer exists for communications transmitted over privately owned, publicly accessed websites, but the act is nonetheless applied in these circumstances. Expanding the legislation further to cover more conduct out-with its intended purpose is therefore undesirable.

\subsubsection{Harassment and Stalking}

NCP distributors may also be prosecuted under stalking ${ }^{77}$ and harassment ${ }^{78}$ laws, as recently confirmed by COPFS guidance, which says there is a strong presumption in favour of instigating proceedings where there is sufficient evidence. ${ }^{79}$ The devastating impact of NCP has also been recognised, alongside the fact that such harassment may constitute domestic abuse. ${ }^{80}$ Nonetheless, sufficiency of evidence as required by the acts is often difficult to establish, since the finding of a 'course of conduct', which must amount to at least two occasions, is central to successful prosecutions. ${ }^{81}$ Even in cases involving two or more

\footnotetext{
${ }^{70}$ A Kitchen, "The Need to Criminalize Revenge Porn: How a Law Protecting Victims Can Avoid Running Afoul of the First Amendment" (2015), 90 Chicago-Kent Law Review 247-300 at2 51.

${ }^{71}$ For example, a woman who sued 'PinkMeth' was then "featured" on the website's homepage, causing her name and photos to be spread more widely: see M.J. Matorin, 'In the real world, revenge porn is far worse than making it illegal' (2013) available at http://talkingpointsmemo.com/cafe/our-current-law-is-completelyinadequate-for-dealing-with-revenge-porn (accessed 9 November 2015).

${ }^{72}$ Communications Act 2003, s.127.

${ }^{73}$ See note 15 (COPFS Guidance) at p.8.

${ }^{74}$ See note 69 (Mitchell) at p.4.

${ }^{75}$ L Edwards, “Section 127 of the Communications Act 2003: Threat or Menace?” (2012) SCL Journal Vol. 23, Issue 4, p.5.

${ }^{76}$ Ibid, p.2.

${ }^{77}$ Criminal Justice and Licensing (Scotland) Act 2010, s.39(1).

${ }^{78}$ Protection from Harassment Act 1997, s.8(1).

${ }^{79}$ See note 15 (COPFS Guidance) at p.5.

${ }^{80}$ Domestic Abuse (Scotland) Act 2011, s.1.

${ }^{81}$ See note 77 at s.39(2)(a); See note 77 at s.8(1); and Domestic Abuse (Scotland) Act 2011, s.2 - inserting s.8A(1) into the Protection from Harassment Act 1997.
} 
incidents, this alone has been insufficient to constitute a course of conduct. ${ }^{82}$ Although some distribution cases will qualify as harassment, stalking, or domestic abuse, the viral spread of an image online tends to result from the Internet's amplification of one single act, which cannot be protected by harassment and stalking laws. ${ }^{83}$

\subsubsection{Threatening or Abusive Behaviour}

Alternatively, perpetrators of NCP may be (and have been), convicted of "threatening or abusive behaviour". ${ }^{84} \mathrm{~A}$ course of conduct is not necessary, since single acts are covered by the legislation, and it is required that the behaviour would be likely to cause a reasonable person to suffer fear or alarm. ${ }^{85}$ However, this offence was established to allow for the prosecution of miscellaneous disorderly conduct crimes that could no longer be prosecuted under the common law offence 'breach of the peace'. ${ }^{86}$ Since it was not designed for the Internet, many victims may be unaware that this offence can be utilised to prosecute NCP.

Not only this, but prosecutions will largely depend on the victim's complaints being taken seriously, yet evidence of apathy from local police and law enforcement to complaints of harassment, stalking, and abusive behaviour has been documented extensively. ${ }^{87}$ Since prosecutors are generally unwilling to pursue NCP perpetrators under these laws, it should be considered whether claims would be taken more seriously if the behaviour was framed as a sexual crime, and the fundamental harms involved in the offence were addressed. This idea will be explored further in section 2.4 , which outlines why a new offence targeting NCP may be desirable.

\subsection{Arguments Against Criminalisation}

\subsubsection{Over-criminalisation}

A new criminal offence addressing NCP is commonly thought to be undesirable since it could result in over-criminalisation. ${ }^{88}$ Over-criminalisation occurs when growing types of conduct become criminalised, making it difficult for the average person to know the law, thus frustrating the supposed deterrence effect of criminal law. "Once everything wrongful is made criminal, society's ability to reserve special condemnation for some forms of misconduct is... lost. ${ }^{.90}$ However, stating that certain behaviour should not be criminalised

\footnotetext{
${ }^{82}$ Lau v DPP [2000] All ER (D) 244.

${ }^{83}$ See note 58 (Levendowski) at p.432.

${ }^{84}$ The Scotsman, "Lanarkshire man avoids jail over "revenge porn" " (2015) available at http://www.scotsman.com/news/scotland/top-stories/lanarkshire-man-avoids-jail-over-revenge-porn-1-3666036 (accessed 9 November 2015).

${ }^{85}$ See note 77 at s. 38 .

${ }^{86}$ The Scottish Government, Stalking and Harassment, http://www.gov.scot/Topics/archive/laworder/harassment/stalkinglaw (accessed 9 November 2015).

${ }^{87}$ See note 58 (Levendowski) at p.425.

${ }^{88}$ See note 37 (Budde) at p.7.

${ }^{89}$ See note 37 (Budde) at p.36.

${ }^{90}$ J.C. Coffee, "Does "Unlawful” Mean "Criminal"? Reflections on the Disappearing Tort/Crime Distinction in American Law" (1991), 71 Boston University Law Review 193-246 at 201.
} 
because too many other types of conduct are already criminalised is at best a non sequitur. ${ }^{91}$ While over-criminalisation may be a problem in some areas of law, for example drug offences, the same cannot be said for sexual violations causing serious harms, such as NCP.92

It has also been argued that criminalising NCP exemplifies 'crime du jour' legislation, where a kneejerk reaction fuelled by media coverage and public outcry leads to higher penalties for 'less serious' crimes, creating disproportionality between the wrong and the punishment. ${ }^{93}$ Such legislation "ends up undermining the criminal code rather than improving it". 94 However, public outcry from numerous campaigns, media outlets, and victims themselves arguably highlights the inadequacy of the multiplicity of overlapping offences in place. Additionally, the reasons NCP should not be considered a "less serious" crime have been outlined; such an objection is arguably another way of trivialising an issue primarily affecting women. ${ }^{95}$

A similar argument is that we should resist reflexively crafting new legislation to address societal problems that are not unique to the Internet. ${ }^{96}$ However, a well-drafted law would not be restricted to online images. ${ }^{97}$ Although the Internet transformed NCP into a widespread, visible problem, it is likely to have always existed on a small scale in more traditional forms. Sexual violations are worthy of legislative action, whether occurring online or offline.

\subsubsection{Freedom of Expression}

Freedom of expression is often referenced in an attempt to justify NCP's legality. ${ }^{98}$ ECHR Article 10 states that everyone has the right to freedom of expression, including expressions "that offend, shock, or disturb..." ${ }^{99}$ However, the exercise of these freedoms is not an absolute right, but "subject to such formalities, conditions, restrictions or penalties... for the protection of the reputation or rights of others, for preventing the disclosure of information received in confidence..." 100 Freedom of expression is not a blanket protection for malicious conduct lacking literary, artistic, political or scientific value simply because it contains an expressive dimension.

Contrary to this free speech rhetoric, a law restricting disclosure of private sexual images could in fact serve important speech enhancing functions. ${ }^{101}$ According to the logic of "free

\footnotetext{
${ }^{91}$ See note 27 (Citron and Franks) at 362.

92 See note 28 , at p. 186 .

${ }^{93}$ K Das "Crime Against Women and the Concept of Overcriminalisation" (2010) National Academy of Legal Studies and Research (NALSAR) University, at 4.

${ }^{94}$ PH Robinson, T Gaeta, M Majarian, M Schultz, and DM Weck, "The Modern Irrationalities of American Criminal Codes: An Empirical Study of Offense Grading” (2010) Faculty Scholarship Paper 298, 100 Journal of Criminal Law and Criminology 709, at735.

${ }^{95}$ See pp.2-3

${ }^{96}$ See note 62 (Stokes) at p.931.

${ }^{97}$ See proposed draft in Appendix, s.3(1).

${ }^{98}$ However, such an argument is far more popular in the USA, due to 1st Amendment rights.

${ }^{99}$ Handyside v UK [1976] ECHR 5.

${ }^{100}$ European Convention on Human Rights, Article 10(2).

${ }^{101}$ See note 50 (Nussbaum) at p.172.
} 
speech' justifications for NCP, a woman's right to self-expression is "less important than a man's right to punish her for that self-expression". ${ }^{102}$ The 'right' to publish sexual images without the subject's consent should not outweigh an individual's right to respect for family and private life, autonomy and dignity in this context. 'Free speech' aiming to humiliate, shame, and silence women should not be deemed worthy of legal protection, since it contributes to a culture in which violence against women is normalised. It is so valueless that there is a compelling interest in restricting it. ${ }^{103}$

\subsection{Benefits of Criminalisation}

\subsubsection{Deterrence}

"The Internet never forgets.",104

Perhaps the primary issue with existing legal remedies is that they may only be utilised after content has been circulated online; publication is not prevented from the outset. ${ }^{105}$ Once an image is online, it is virtually impossible to remove, so preventing the conduct from occurring in the first place must be paramount. Recent non-consensual distribution of celebrities' images highlights this issue. Although they, more than anyone, have the financial resources and power to have content removed, a huge portion of the world have viewed their images. Many viewers will have these photos saved, which could be spread online once again at any point.

The recent rise of NCP is also likely to be related to the fact that perpetrators have little incentive to refrain from such behaviour. Distributors are unlikely to fear a course of action that is unlikely to materialise, such as being sued, but they would perhaps be afraid of a criminal conviction, since "that shows up on their record forever". ${ }^{106}$ Given the inherent failure of the current legal framework in adequately protecting victims, it seems that deterrence may only be achieved by a new criminal offence. This is partly due to the stigma that attaches to criminal sanctions, which would serve important expressive values by conveying social condemnation to those who distribute sexual images without consent. ${ }^{107}$

\subsubsection{The Expressive Function of Law}

An important aspect of criminal law is this expressive function; it creates and shapes social mores, guiding people in their choices by setting out authoritative norms for behaviour. ${ }^{108}$ Criminalising NCP could be the most powerful force in sending the clear message that such

\footnotetext{
${ }^{102}$ New Statesman, "Laurie Penny on web misogyny: It's time to end the culture of online misogyny" (2013) available at http://www.newstatesman.com/laurie-penny/2013/01/laurie-penny-its-time-end-culture-onlinemisogyny (accessed 9 November 2015).

${ }^{103}$ E. Volokh, "Freedom of Speech and Information Privacy: The Troubling Implications of a Right to Stop People from Speaking About You” (2000) 52 Stanford Law Review 1049, at1116.

${ }^{104}$ See note 45 (Larkin) at p.1.

${ }^{105}$ See note 69 (Mitchell) at p.1.

${ }^{106}$ See note 69 (Mitchell) at p.9.

${ }^{107}$ See note 54 (Bambauer) at p.2085.

${ }^{108}$ D.K. Citron, "Laws Expressive Value in Combatting Cyber Gender Harassment" (2010) 108 Michigan Law Review 373, p.407.
} 
egregious violations of sexual autonomy are unacceptable and deserving of punishment. ${ }^{109}$ Criminalisation would recognise the destructive consequences of NCP and challenge harmful, out-dated attitudes by reconceptualising it as a sexual violation. The lack of legislative action thus far could be said to imply that such behaviour should be tolerated.

In fulfilling its expressive function, criminal law must also adhere to the principle of 'fair labelling,, which states that the law should fairly capture distinctions between types of wrongdoing in order to symbolise the appropriate level of condemnation to be attributed to the offender. ${ }^{110}$ Some criminal theorists go so far as to argue that fair labelling is crucial for determining just punishment. ${ }^{111}$ Since society's concept of what conduct is 'criminal' changes over time, particularly when technological advances create new ways for crimes to be carried out, fair labelling requires the creation of an appropriately defined crime to reflect it. ${ }^{112}$ This highlights an aspect absent from existing methods of regulation; emphasis on the 'type of wrongdoing' pervading NCP. A new offence should therefore address and punish its true harms - sexual violation, lack of consent, and objectification - the same harms animating the majority of sexual offences.

\section{Criminalisation: A Comparative Analysis}

Since it has been established that existing remedies do not provide adequate redress for NCP victims in Scotland and that criminalising such behaviour may be advantageous, it is crucial to explore how this should be done. The successes and failures of laws addressing NCP in other jurisdictions will therefore be analysed, in order to outline how a law ought to be effectively drafted in Scotland.

\subsection{England and Wales}

An amendment to the Criminal Justice and Courts Act criminalises NCP in England and Wales as of Spring 2015. ${ }^{113}$ Those found guilty will face a fine and/or a maximum of two years in prison. Since there is a high probability that in the event of criminalisation, Scotland may adopt an approach similar to England and Wales, it is perhaps the most relevant legislation to critique.

For an offence to be committed, a "private sexual photograph or film" must be disclosed without the subject's consent, "with the intention of causing that individual distress". ${ }^{114}$ However, NCP is not only disseminated in the context of 'revenge', where the perpetrator's intend to cause the victim harm. Perpetrators may be driven by a multitude of varying motivations: for money, entertainment, sexual gratification, notoriety, or even for no particular reason. This further highlights why the term 'revenge porn' may be undesirable, it

\footnotetext{
${ }^{109}$ See note 13 (Citron) at p.377.

${ }^{110}$ M. Plaxton, J. Chalmers and F. Leverick, "Fair Labelling in Criminal Law" (2008), Modern Law Review 71, pp.217-246, p.226.

${ }^{111}$ D. Husak, "The Costs to Criminal Theory in Supposing that Intentions are Irrelevant to Permissibility" (2009)3 Criminal Law and Philosophy 51-70, at 64.

${ }^{112}$ B. Mitchell, "Multiple Wrongdoing and Offence Structure: A Plea for Consistency and Fair Labelling" (2001) 64 Modern Law Review 393, at412.

${ }^{113}$ Criminal Justice and Courts Act 2015.

${ }^{114}$ Ibid, s.33(1)(b).
} 
not only trivialises a serious offense, but is arguably partially to blame for misguided intent requirements being drafted into law. While it is crucial that the actus reus and the mens rea are clearly stated, this requirement arbitrarily distinguishes between perpetrators motivated by a desire to harm the victim, and those motivated by other reasons, although the ultimate effects remain the same. ${ }^{115}$ A pertinent example of this is the recent disclosure of images of celebrities; the distributor's motive in this case was to gain online currency; any distress caused was a mere side effect. ${ }^{116}$

Additionally, the Act states that the defendant is not presumed to have intended to cause distress "merely because that was a natural and probable consequence of the disclosure", implying that the burden of proof lies with the victim. ${ }^{117}$ Proving a person's intentions may be extremely difficult, and could create a loophole in the law for defendants seeking to avoid culpability. Since the significant element is lack of consent, it should suffice that the perpetrator ought to have reasonably known that consent was lacking. Intent would thus be found for reckless disclosures, making it the perpetrator's responsibility to obtain affirmative consent prior to distribution. ${ }^{118}$ An offence in Scotland should adopt such an approach. ${ }^{119}$

The Act defines private as "something that is not of a kind ordinarily seen in public". ${ }^{120}$ The accompanying explanatory notes state that this definition seeks to exclude 'sexual' acts that would normally be seen in public, such as people kissing. However, this definition is fairly ambiguous and appears to be borrowed from the voyeurism provision within the Sexual Offences Act 2003. ${ }^{121}$ The term 'reasonable expectation of privacy' may be more appropriate since it is widely used in legal reasoning, and privacy can be reasonably expected even in public or semi-public spaces, particularly when the activity is inherently private. ${ }^{122}$ Consent to the recording of a private act in a public place would not be equated with consent to the wide distribution of said recording.

The definition of sexual is fairly expansive; specific exposed body parts are outlined, and a reasonable person standard is also incorporated to cover an image that is sexual "because of its nature" or because of its content "taken as a whole". ${ }^{123}$ A sexual image therefore does not necessarily require nudity, for example, an image of a fully clothed person performing a sex act would be included. Similar wording should be adopted in Scotland to ensure that all sexual conduct is protected. ${ }^{124}$

\footnotetext{
${ }^{115}$ M.A. Franks, "Drafting an Effective "Revenge Porn" Law: A Guide for Legislators" (2015) University of Miami Law School, (August 17, 2015) available at SSRN: http://ssrn.com/abstract=2468823, at5.

${ }^{116}$ R. Price, "Bitcoin beggars try to profit off leaked celebrity nudes" (2014) available at http://www.dailydot.com/crime/celebgate-jennifer-lawrence-nude-leakers-bitcoin/ (accessed 9 November 2015).

${ }^{117}$ See note 113 at s.33(8).

${ }^{118}$ T. Linkous, "It's Time for Revenge Porn to Get a Taste of its Own Medicine: An Argument for the Federal Criminalization of Revenge Porn” (2014) 20 Richmond Journal of Law \& Technology 14, p.12.

${ }^{119}$ Appendix, s.1(1)(c).

${ }^{120}$ See note 113 at s.35(2).

${ }^{121}$ Sexual Offences Act 2003, s.68(1)(c).

${ }^{122}$ Appendix, s.3(4).

${ }^{123}$ See note 113 at s.35(3)(b)\&(c).

${ }^{124}$ Appendix, s.3(5).
} 
Circumstances are also outlined where an image containing private/sexual content will be excluded from being regarded as 'private and sexual' for the purposes of the offence. ${ }^{125}$ For example, a pornographic image with the victim's face superimposed onto it would be excluded from the Act's ambit. A similar exception could be adopted in Scotland, since such images that technically contain private/sexual content do not violate a person's sexual autonomy. ${ }^{126}$

Three defences are set out in the Act. Firstly, it is a defence to show reasonable belief that the disclosure was "necessary for the purposes of preventing, detecting or investigating crime", which seemingly aims to allow for cooperation with law enforcement during criminal investigations. ${ }^{127}$ Secondly, it is a defence to show reasonable belief that an image published in journalistic material is in the public interest. ${ }^{128}$ Finally, it is a defence to show reasonable belief that the image had been previously disclosed for reward "either by the individual depicted or by another", and that there was no reason to believe that the disclosure was made without consent. ${ }^{129}$ This section is designed to protect those who distribute what they thought to be commercial pornography. ${ }^{130}$

Although these provisions seem fair, a 'reasonable belief' is established for the second and third defences if evidence is adduced "to raise an issue with the respect to it, and the contrary is not proved beyond reasonable doubt". ${ }^{131}$ This means that the victim would need to prove that the perpetrator could not have reasonably believed that the image had previously been disclosed consensually for reward. This may be an unfair burden of proof to place on the complainant, since it could be difficult to demonstrate that a reasonable person would not have presumed that the victim consented to distribution. If NCP is criminalised in Scotland, it should be the defendant's responsibility to prove that they reasonably believed the victim had consented and the burden of proof should not be placed on the victim. ${ }^{132}$

Schedule 8 of the Act extends liability to providers of information society services established in England and Wales, which adopts a 'notice and takedown' approach mirroring the E-Commerce Directive. ${ }^{133}$ Exceptions are granted provided that certain conditions are met. For example, Internet Service Providers (ISPs) hosting content can avoid liability if they act expeditiously to disable access to the image after obtaining knowledge of its illegality. ${ }^{134}$ Hopefully this schedule will be useful in aiding the removal of victim's images from the Internet, and Scotland should consider a similar approach. Although it is limited in effectiveness since it cannot apply to ISPs out-with England and Wales, swift responses from hosting websites may help diminish the gravity of this issue. Prominent social media websites

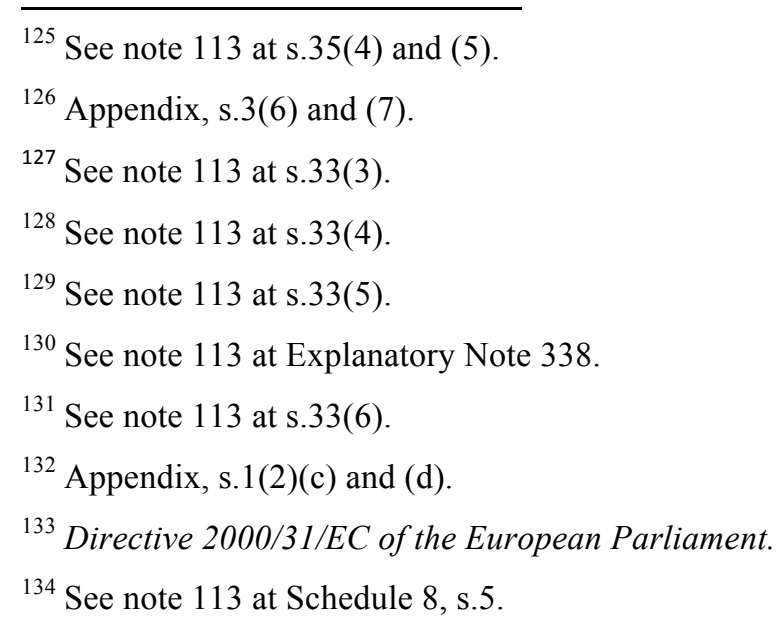


have recently recognised NCP as a form of sexual violence in their user policies, stating that those who share images without permission will have their account restricted or removed. ${ }^{135}$

There are other aspects of the approach taken in England and Wales that Scotland may want to take note of when considering criminalisation. The UK Government have launched a 'revenge porn helpline', providing victims with free, confidential advice on available remedies. ${ }^{136}$ The helpline liaises with law enforcement and media companies to remove illegal postings where possible, and directs victims to other support services. In the helpline's first six months, over 1,800 calls have been taken, so it appears to be a positive step that is encouraging victims to report offences. ${ }^{137}$

\subsection{The USA}

The USA has been leading the way for criminalization of NCP, with states enacting legislation against the conduct from 2013 onwards. However, several of America's legislative attempts have been criticised for being under-inclusive in terms of the type of images covered. ${ }^{138}$ State legislation may also be limited in effectiveness in the absence of a Federal law, due to ISP immunity within the Communications Decency Act. ${ }^{139}$ Nonetheless, it is helpful to explore approaches taken in the US in order to highlight issues to avoid, and efforts that could be adopted in Scotland.

\subsubsection{California}

California's first NCP law enacted, Senate Bill $255,{ }^{140}$ was written very narrowly; it applied only to a person who creates an image and subsequently distributes it, thus leaving 'selfies' unprotected and potentially covering only $17 \%$ of victims. ${ }^{141}$ A law excluding victims who took the image themselves could contribute to harmful victim-blaming mentalities, as discussed previously. ${ }^{142}$ The wording also created multiple other loopholes and was heavily criticised by commentators. ${ }^{143}$ For instance, redistributed images, and those obtained via theft/hacking would also be excluded from the legislation's ambit. ${ }^{144}$ Fortunately, these

\footnotetext{
${ }^{135}$ https://www.facebook.com/communitystandards; https://support.twitter.com/articles/18311-the-twitter-rules (accessed 9 November 2015).

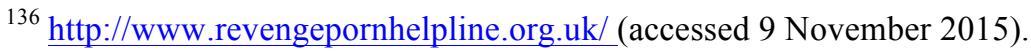

${ }^{137}$ Government Press Release (2015) available at https://www.gov.uk/government/news/hundreds-of-victimsof-revenge-porn-seek-support-from-helpline (accessed 9 November 2015).

${ }^{138}$ See note 118 (Linkous).

139 "No provider or user of an interactive computer service shall be treated as the publisher or speaker of any information provided by another information content provider" (47 U.S. Code $\$ 230(\mathrm{c})(1))$; however, this exemption does not apply to federal criminal statutes (47 U.S. Code $\$ 230(e)(1)$ ).

${ }^{140}$ CAL. PENAL CODE $\S 647(\mathrm{j})(4)(\mathrm{A})$.

${ }^{141}$ Since roughly $83 \%$ of images originate as 'selfies': see note 27 (Citron and Franks) at p.350.

${ }^{142}$ See pp.13-14.

${ }^{143}$ C Calvert, "Revenge Porn and Freedom of Expression: Legislative Pushback to an Online Weapon of Emotional and Reputational Destruction” (2014), 24 Fordham Intellectual Property, Media \& Entertainment. Law Journal 673, at689-690; see note 62 (Stokes) at 943; see note 20 (Salter and Crofts) at 246; see note 28 (Citron) at 149.

${ }^{144}$ See note 118 (Linkous) at 9.
} 
criticisms were reflected upon, and an amendment was introduced to broaden the law, which now includes 'selfies' and redistribution. ${ }^{145}$

Nonetheless, several problematic aspects of the amended Californian law remain that Scots law should aim to avoid. In a similar fashion to England and Wales', California's bill requires that the perpetrator knows or should have known that distribution of the image would cause the victim "serious emotional distress", and the depicted person must have subsequently suffered that distress. ${ }^{146}$ This element has been criticised by scholars for the same reasons highlighted in respect to the Criminal Justice and Courts Bill - it narrows the ambit of the law unnecessarily. ${ }^{147}$

California's statute also only applies in circumstances where the parties "agree or understand that the image shall remain private", but no guidance is provided in finding what constitutes an agreement or understanding. ${ }^{148}$ The loose wording used here means that the statute is unlikely to be applied to an image distributed recklessly, even when the perpetrator knew or should have reasonably known that the subject did not consent. Scots law should aim to avoid this kind of wording since it could make convictions difficult or even impossible; the burden of proof should be on the defendant to show that explicit consent was obtained. ${ }^{149}$

Lastly, those prosecuted under Californian law are found to be guilty of disorderly conduct (a misdemeanour), punishable by up to six months in prison and a $\$ 1,000$ fine. Such a penalty is arguably weak, and potentially ineffective as a deterrent. ${ }^{150}$ Since one of the primary purposes of criminal law is deterrence, harsher punishment may be necessary. ${ }^{151}$ In the event that Scotland criminalises NCP, harsher penalties should perhaps be considered. ${ }^{152}$

\subsubsection{Illinois}

Perhaps one of the seemingly most effective NCP laws implemented in the US so far is that of Illinois, ${ }^{153}$ modelled after legislation drafted by Professor Mary Anne Franks. ${ }^{154}$ It categorises NCP as a Class 4 Felony offence, punishable by up to three years in prison and a fine of up to $\$ 25,000 ;{ }^{155}$ a fairly harsh punishment, which should sufficiently deter potential perpetrators. The Bill also provides restitution to victims and requires the perpetrator to forfeit any profits derived from the distribution of the material. ${ }^{156}$

\footnotetext{
${ }^{145}$ Senate Bill 1255, amending CAL. PENAL CODE $\$ 647$.

${ }^{146}$ Ibid, $\$ 647(\mathrm{j})(4)(\mathrm{A})$.

${ }^{147}$ See note 20 (Salter and Crofts) at 246; see note 115 (Franks) at 5.

${ }^{148}$ See note 140 .

149 Appendix, s.3(3).

${ }^{150}$ See note 27 (Citron and Franks) at p.389.

${ }^{151}$ As discussed at pp.27-18.

${ }^{152}$ Appendix, s.2(1).

${ }^{153}$ Illinois Criminal Code of $2012 \S 11.23 .5$ (b)(1).

${ }^{154}$ See note 115 (Franks) at p.5.

${ }^{155}$ See note $153, \S 11-23.5(\mathrm{f})$.

${ }^{156}$ See note $153, \S 124 B-500(1)$.
} 
Illinois' law makes prosecuting NCP distributors easier because it doesn't require proof of intent to cause harm. The bill is also not only applicable to the original perpetrator; instead, the law targets downstream distributors using a 'reasonable person' standard to find whether the perpetrator knew or ought to have known that the person depicted did not consent to dissemination. ${ }^{157}$ This provision helps prevent material from being circulated online when it is clear that consent is lacking, giving priority to the harm done to victims, rather than protecting those who recklessly distribute second-hand images. Scotland may want to adopt a similar reasonable person standard to include reckless distribution. ${ }^{158}$

Several exemptions are laid out in Illinois' legislation, which bear similarities to England and Wales' defences. However, images involving "voluntary exposure in public or commercial settings" are also exempt from the provisions. ${ }^{159}$ Although this may appear to be equivalent to the 'disclosure for reward' defence, the 'public' element could potentially raise issues. For example, consent to the recording of a sexual act in a technically 'public' place is not the same as consent to wide distribution of that recording. Once again, lack of consent to dissemination should be the primary feature of the offence, so this type of defence should not be adopted in Scotland.

\subsection{Israel}

Israel is the first jurisdiction to recognise those targeted by NCP as victims of sexual harassment. ${ }^{160}$ The legislation was codified as an amendment to Israel's Prevention of Sexual Harassment law, ${ }^{161}$ which criminalises the distribution of an image that focuses on a person's sexuality if it is done without the subject's consent, under circumstances that are likely to degrade or humiliate him/her. ${ }^{162}$ This wording seems to be sufficiently inclusive, since reckless acts are covered and intent to cause distress is not required.

Offenders are punishable by up to five years imprisonment, and the victim can also subject the perpetrator to civil liability. ${ }^{163}$ A court may award compensation of up to NIS 50,000, without the need to prove concrete damage caused to the victim, and higher compensation may be awarded if damage is proven. ${ }^{164}$ The law also states that courts should not impose any burdens of proof on victims that may deter them from filing actions. ${ }^{165}$ Scotland should also adopt an approach that provides appropriate punishment ${ }^{166}$ and encourages victims to come forward. ${ }^{167}$

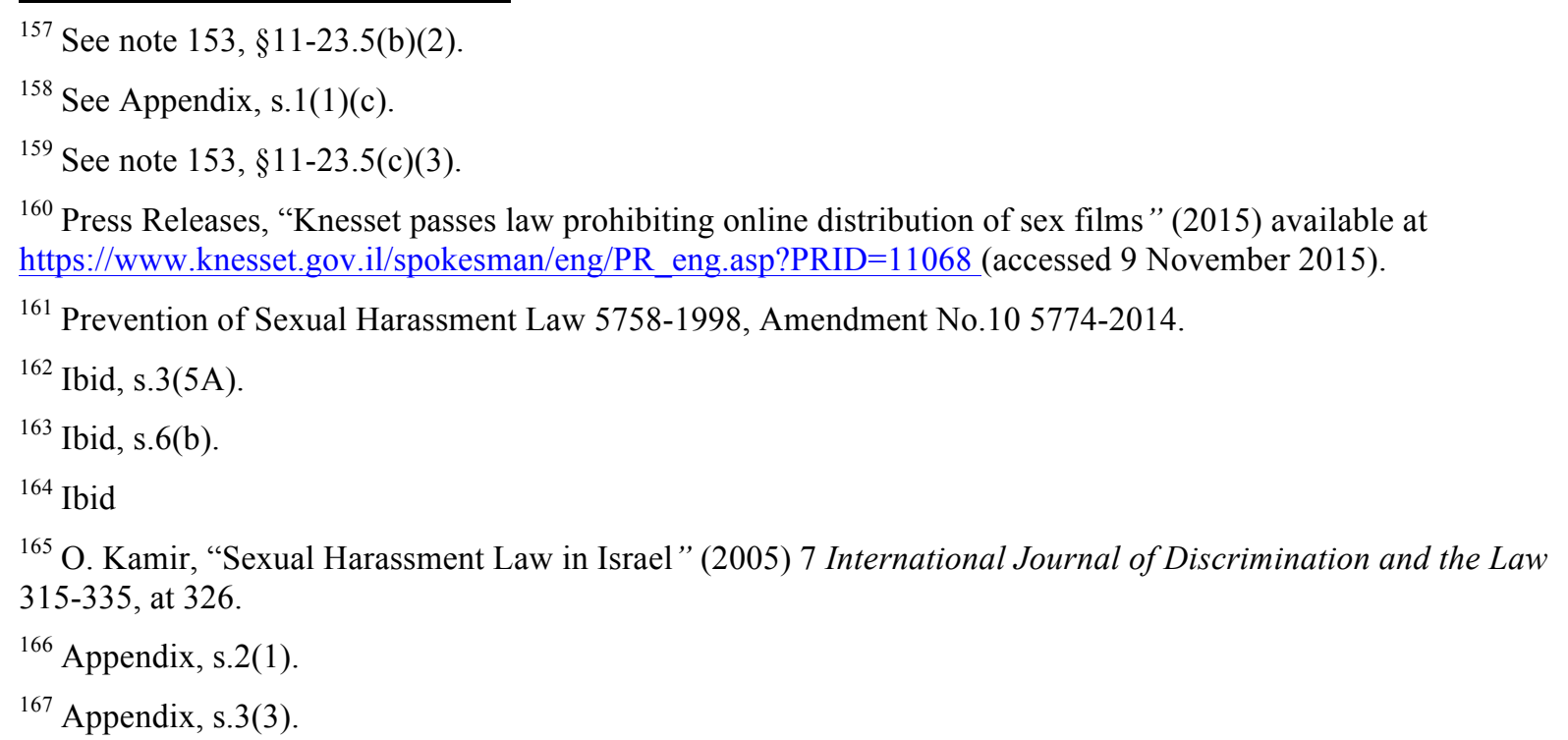


A controversial aspect of classing NCP as a form sexual harassment is that perpetrators will be classed as sexual offenders. In Scotland, a person sentenced to more than two and a half years imprisonment for a relevant sexual offence is required to sign the sex offender's register for an indefinite period. ${ }^{168}$ This raises a number of issues, since adolescents who foolishly share an image online could potentially be labelled a sex offender for years later. ${ }^{169}$ However, it is common for an offender to be subject to notification requirements only if certain conditions are fulfilled, for example, if he/she was over 18 at the time of the offence. If NCP is defined as a sexual offence in Scotland, a similar condition could be attached to notification requirements. From a more positive perspective, the stigma that tends to be associated with registered sex offenders may act as a further deterrent.

Another advantage is that victims would be regarded as 'vulnerable witnesses', ${ }^{170}$ and can therefore be granted automatic protections in court and an anonymity order. ${ }^{171}$ Although anonymity may be of limited value in some cases, it could be incredibly valuable in encouraging victims to come forward. For example, news articles reporting convictions of NCP under the Malicious Communications Act 1998 have often named the victim, risking exacerbating the problem and aiding further re-victimisation. ${ }^{172}$ As previously discussed, labelling NCP as a sexual offence could also be crucial to emphasise the type of wrongdoing pervading the offence.

\section{Conclusion}

Ultimately, NCP appears to be indicative of a broader misogynistic culture in which disrespect for women's sexual privacy is endemic. Until attitudes towards women and consent are transformed, and harmful cultural norms are effectively tackled, it seems that the problem may persist. Nonetheless, since the law can be said to reflect cultural values about female sexuality, ${ }^{173}$ it should no longer tolerate sexual violations online. Scotland's current legislative framework is not sufficiently tailored to protect victims adequately, and it is clear that action must be taken. Although NCP is unlikely to be eradicated by any one measure, criminalisation seems the most worthwhile method of deterring perpetrators and acknowledging its detrimental impact on gender equality. This form of 'cyber misogyny' should be treated as the harmful, discriminatory conduct that it is to prevent the normalisation of non-consensual sexual activity and to empower victims to demand redress and accountability.

\footnotetext{
${ }^{168}$ Sexual Offences Act 2003, s.82.

${ }^{169}$ T. Thomas, “Children and Young People on the UK Sex Offender Register” (2009) International Journal of Children's Rights 491-500.

${ }^{170}$ The definition of a 'vulnerable witness' in criminal proceedings includes victims of sexual offences s.271(1)(c)(i) of the Criminal Procedure (Scotland) Act 1995, as amended by s.10 of the Victims and Witnesses (Scotland) Act 2014.

${ }^{171}$ s.271N of the Criminal Procedure (Scotland) Act 1995, as amended by s.90 of the Criminal Justice and Licensing (Scotland) Act 2010; Contempt of Court Act 1981, s.11.

172 The Telegraph, "Fallen out with a friend? Revenge porn is the new price to pay" (2015) available at http://www.telegraph.co.uk/women/womens-life/11363238/Revenge-porn-is-the-new-price-to-pay-for-a-falloutwith-friends.html (accessed 9 November 2015).

${ }^{173}$ C. Smart, 'Feminism and the Power of Law' (London; New York: Routledge 1989), p.26.
} 
Distribution of NCP should therefore be established as a sexual offence in Scotland. Appendix A outlines recommendations as to how this legislation should be effectively drafted, in the form of an amendment to the Sexual Offences (Scotland) Act 2009. The successes and failures of legislation enacted in other jurisdictions have been considered in establishing this draft, which seeks to emulate effective aspects of these statutes, while acknowledging scholarly critiques in endeavouring to improve upon them. The legislation aims to be broad enough to encompass the vast majority of victims; it covers online and offline distribution, relevant terms are broadly defined to encompass varieties of offending material and methods of distribution. Intent to cause distress is not necessary allowing protection from reckless distribution. Defences are outlined to protect innocuous distributors. It also provides sufficiently harsh penalties, allows for the destruction of offending images, and requires the forfeiture of profits from perpetrators. Primarily, it aims to define NCP as a sexual violation and emphasises the importance of obtaining affirmative consent prior to distribution, placing the burden of proof on the perpetrator. 


\section{$\underline{\text { APPENDIX - Draft Legislation }}$}

\section{Amendment to the Sexual Offences (Scotland) Act 2009}

\section{Section 1 Non-consensual disclosure of a private sexual image}

(1) A person commits an offence if he or she -

(a) intentionally discloses a private sexual image of an individual without their consent, and

(b) knows that the individual did not consent to the disclosure, or

(c) should have reasonably known that the individual did not consent to the disclosure

(2) It is a defence for a person charged with an offence under this section to show that he or she reasonably believed -

(a) the disclosure to be in the public interest

(b) the disclosure to be necessary for the purposes of preventing, detecting or investigating crime ${ }^{174}$

(c) that the image had been previously disclosed for commercial purposes by the individual mentioned in subsection 1

(d) that the image had been previously disclosed for commercial purposes by another person, with the consent of the individual mentioned in subsection 1 .

\section{Section 2 Penalties}

(1) A person guilty of a Section 1 offence is liable -

(a) on summary conviction, to imprisonment for a term not exceeding 12 months or a fine not exceeding the statutory maximum (or both)

(b) on conviction on indictment, to imprisonment for a term not exceeding 5 years or a fine (or both). ${ }^{175}$

(2) In addition to any penalties the court may impose, the court may order the destruction of an image violating section $1 .{ }^{176}$

(3) A person who commits the offence of non-consensual disclosure of a private sexual image forfeits any profits, proceeds, or property acquired in violation of section $1 .{ }^{177}$

\footnotetext{
${ }^{174}$ See note 113 at s.33(3).

${ }^{175}$ Sexual Offences (Scotland) Act 2009, s.48.

${ }^{176}$ Hawaii Revised Statutes §711-1110.9(2).
} 


\section{Section 3 Definitions}

For the purposes of this section -

(1) 'Disclose' includes transferring, transmitting, publishing, distributing, reproducing, selling, or making an image available to a person by any other means.

(2) 'Image' includes a film, photograph, videotape, digital recording, or any other depiction, including data stored by any means that is capable of conversion into an image. Drawings are not included.

(3) 'Consent' means free agreement. It is presumed that the individual mentioned in section 1 did not consent to disclosure of a private sexual image. This presumption must be overcome with evidence of the individual's explicit consent.

(4) An image is 'private' if created in circumstances where the individual mentioned in section 1 retains a reasonable expectation of privacy.

(5) An image is 'sexual' if -

(a) it shows all or part of an individual's genitals, anus, or pubic area;

(b) it shows genital, anal, or oral sex, masturbation, or any other sexual activity;

(c) it shows something that a reasonable person would consider to be sexual. ${ }^{178}$

(6) Subsection (4) applies in the case of $-{ }^{179}$

(a) an image that has been altered in any way,

(b) an image that has been combined with another image or images, and

(c) an image that has been combined with something else

(7) The image is not private and sexual if -

(a) it does not consist of or include an image that is itself private and sexual

(b) it is only private or sexual by virtue of the alteration or combination mentioned in the previous subsection, or

(c) it is only by virtue of the alteration or combination mentioned in subsection (3) that the individual mentioned in section (1) is shown as part of, or with, whatever makes the image private and sexual

\footnotetext{
${ }^{177}$ See note 153 at $§ 124 B-500(1)$.

${ }^{178}$ See note 113 at s.35(3)(b).

${ }^{179}$ See note 113 at s.35(4) and (5).
} 